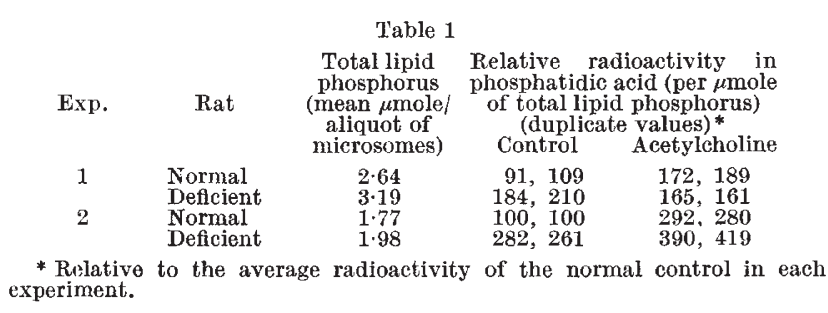

choline and increased the rate of uptake of phosphorus-32 into phosphatidic acid to a level as great or greater than that in the stimulated but intact microsomes. Various workers have investigated the effect of essential fatty acid deficiency on the structure of cell membranes giving evidence that the skin of rats deficient in essential fatty acids is more permeable to water than that of normal rats ${ }^{6}$, their erythrocytes and capillarios are more fragile? and that liver mitochondria from deficient rats are more easily damaged than normal mitochondria ${ }^{8}$. Also, Collins ${ }^{4}$ has shown that after in vivo injection of phosphorus-32 into deficient rats the uptake by liver lecithin and phosphatidyl ethanolamine is greater than in the normal rat. These results are all consistent with the view that a deficiency of essential fatty acids weakens lipoprotein membranes. In the experiments recorded here the deficiency of essential fatty acids could have caused the microsomal membrane to disrupt more easily thus leading to an increased uptake of phosphorus-32 into the phosphatidic acid.

We thank the National Health and Medical Research Council of Australia for financial support of this investigation.

$$
\text { G. G. DE PURY }
$$$$
\text { F. D. Collins }
$$

Russell Grimwade School of Biochemistry, University of Melbourne.

${ }^{1}$ Hokin, L. E., and Hokin, M. R., J. Biol. Chem., 234, 1387 (1959).

${ }^{2}$ Hokin, M. R., and Hokin, L. E., J. Biol. Chem., 234, 1381 (1959).

${ }^{3}$ Aaes-Jørgensen, E., Physiol. Rev., 41, 1 (1961).

" Collins, F. D., Biochem. Biophys. Res. Comm., 9, 289 (1962).

${ }^{5}$ Hokin, L. E., and Hokin, M. R., J. Biol. Chem., 233, 822 (1958).

- Basnayake, V., and Sinclair, H. M., Biochemical Problems of Lipids, 476 (Butterworths, London, 1956).

${ }^{7}$ Macmillan, A. L., and Sinclair, H. M., Essential Fatty Acids, 208 (Butterworths, London, 1958). Kramer, J., and Levine, V. E., J. Nutrition, 50, 149 (1953).

${ }^{8}$ Hayashida, T., and Portman, O. W., Arch. Biochem. Biophys., 91, 206 (1960). Levin, E., Johnson, R. M.,, and Albert, S., J. Biol. Chem. 228, 15 (1957).

\section{Lipoamino-acids from Bacillus megaterium}

IT has recently been reported by Macfarlane' ${ }^{1}$ that lipoamino-acids are probably of general occurrence in bacteria, and that they may easily be isolated in good yield if a suitable extraction procedure is selected. It was further shown ${ }^{1}$ that these lipoamino-acids could be characterized with reasonable certainty as $O$-amino-acid esters of phosphatidyl-glycerol. We now report that some of the lipoamino-acid complexes obtainable from Bacillus megaterium $^{2}$ appear to have this same structure. The phosphorus-containing fraction ${ }^{1}$ of Hunter and Goodsall ${ }^{2}$ was dissolved in ether and shaken at $20^{\circ}$ for 30 min with an equal volume of N/15 sodium hydroxide (cf. Macfarlane $\left.{ }^{1}\right)$. This procedure reduced the nitrogen content of the ether phase from 2.5 per cent to less than $0 \cdot 1$ per cent. At the same time, the lipid became oxidizable by periodic acid with the formation of formaldehyde. Using $0.04 \mathrm{M}$ periodic acid in chloroform-95 per cent acetic acid, $569 \mu \mathrm{g}$ of the original lipoamino-acid complex yielded $0.69 \mu$ mole of formaldehyde after the alkaline treatment (estimated by chromotropic acid; calculation for the $O$-leucyl ester of pentadecanoylpalmitylglycerylphosphorylglycerol $=0.71 \mu \mathrm{mole})$. After complete hydrolysis of the lipoamino-acid complex, the only organic compound detect-

\begin{tabular}{|c|c|c|c|c|}
\hline Fatty acids & $\underset{\%}{\text { Neutral }}$ & $\begin{array}{c}\text { Phospho- } \\
\text { lipid } \\
\%\end{array}$ & $\begin{array}{c}\text { Acetone extractable } \\
\text { lipoamino-acid } \\
\text { complexes } \\
\%\end{array}$ & $\begin{array}{c}\text { Lipoarginine } \\
\text { complex }\end{array}$ \\
\hline$n-\mathrm{C}_{12}$ & $0 \cdot 31$ & $0 \cdot 1$ & $2 \cdot 1$ & $<0.05$ \\
\hline$b r-C_{13}$ & $<0.05$ & $<0.05$ & $<0.05$ & $<0.05$ \\
\hline$n-\mathrm{C}_{13}$ & $<0.05$ & $<0.05$ & $<0.05$ & $<0.05$ \\
\hline$b r-C_{14}$ & $3 \cdot 7$ & $13 \cdot 1$ & $11 \cdot 4$ & $<0.05$ \\
\hline$n-\mathrm{C}_{14}$ & $2 \cdot 9$ & $5 \cdot 9$ & $3 \cdot 4$ & $<0.05$ \\
\hline$h b r-C_{15}$ & $24 \cdot 8$ & $34 \cdot 9$ & $37 \cdot 0$ & $3 \cdot 8$ \\
\hline$n-\mathrm{C}_{15}$ & $2 \cdot 6$ & $3 \cdot 8$ & $2 \cdot 3$ & $0 \cdot 7$ \\
\hline$h b r-\mathrm{C}_{16}$ & $1 \cdot 4$ & $0 \cdot 7$ & 0.9 & $<0.05$ \\
\hline$b r-\mathrm{C}_{16}$ & $8 \cdot 0$ & $7 \cdot 1$ & $11 \cdot 6$ & $5 \cdot 1$ \\
\hline $\mathrm{C}_{10}$ monoene & $14 \cdot 1$ & $7 \cdot 8$ & $11 \cdot 6$ & $6 \cdot 3$ \\
\hline$n-C_{16}$ & $15 \cdot 1$ & $22 \cdot 1$ & $9 \cdot 6$ & $24 \cdot 1$ \\
\hline $\begin{array}{l}h b r-\mathrm{C}_{17} \\
2 \text { acids? } b r-\mathrm{C}_{17}\end{array}$ & $\begin{array}{l}0 \cdot 7 \\
5 \cdot 6\end{array}$ & $\begin{array}{l}0 \cdot 5 \\
4 \cdot 5\end{array}$ & $<\begin{array}{l}0.05 \\
7.0\end{array}$ & $\begin{array}{l}1 \cdot 2 \\
7 \cdot 4\end{array}$ \\
\hline$? n-\mathrm{C}$ & $1 \cdot 4$ & 0.5 & $<0.05$ & $5 \cdot 8$ \\
\hline Linoleic & $4 \cdot 6$ & $<0.05$ & $<0.05$ & $<0.05$ \\
\hline Olei & $11 \cdot 2$ & $3 \cdot 7$ & $2 \cdot 7$ & $23 \cdot 6$ \\
\hline$n-\mathrm{C}_{1}$ & 9 & $1 \cdot 8$ & $<0.05$ & $15 \cdot 2$ \\
\hline & 0.05 & $<0$ & $<0.05$ & $6 \cdot 6$ \\
\hline
\end{tabular}

$h$, Highly ; $b r$, branched chain ; $n$, straight chain.

able apart from amino- and carboxylic-acids was glycerol, which was isolated as the crystalline tribenzoate.

Macfarlane's experiments ${ }^{1}$ have further shown that the bulk of the phospholipid in Clostridium welchii, and possibly also in other micro-organisms, can be bound to amino-acids in this way. This finding makes rather less likely the suggestion of Hunter and Godson ${ }^{3}$ that these complexes might be transient intermediates concerned in the transfer of amino-acid residues from a nucleic acid template to a phospholipid surface in the course of the biosynthesis of lipoproteins. If these complexes do indeed occur generally in such large concentrations, then the suggestion of Gaby, Wolin and Zajac ${ }^{4}$ that they are concerned in amino-acid transport processes may prove to be more accurate. However, there does appear to be a certain degree of specificity in the structure of a given lipoamino-acid complex. The complexes described by Hunter and Goodsall ${ }^{2}$ were, in general, extractable with acetone, but the arginine complex was insoluble under these conditions, and could be obtained together with the bulk of the phospholipids by subsequent extraction with methanol. A batch of the lipoarginine complex was prepared in this way and labelled with $\mathrm{DL}-\left[{ }^{14} \mathrm{C}\right]$ arginine. After chromatography on DEAE-cellulose ${ }^{2}$, the lipoarginine complex was converted into the reineckate (159 mg. $10 \mathrm{~m} \mu \mathrm{c}$.) with ammonium reineckate, and recrystallized from ammonium reineckate solution. In this way, although the yield of reineckate was only $20-25$ per cent, it was freed from contaminating phospholipids. After saponification, and conversion of the fatty acids formed to the methyl esters ${ }^{5}$, the composition of the fatty acids in the lipoarginine complex(es) was compared with that of those present in the bulk of the lipoamino-acid complexes (Table 1). Table 1 also includes the fatty acid composition of the bulk neutral lipids and phospholipids of $B$. mega. terium. It can be seen that the fatty acid composition of the lipoarginine complex(es) differs strikingly from that of the acetone-extractable complexes. The significance of this finding in terms of the specific metabolism of individual amino-acids is not, however, clear at the present time.

\section{G. D. Hunter}

Agricultural Research Council

Institute for Research on Animal Diseases, Compton, Newbury, Berks.

A. T. JAMES

Unilever Research Laboratory,

Colworth House, Sharnbrook, Beds.

${ }^{1}$ Macfarlane, M. G., Nature, 196, 136 (1962).

${ }^{2}$ Hunter, G. D., and Goodsall, R. A., Biochem. J., 78, 564 (1961).

${ }^{3}$ Hunter, G. D., and Godson, G. N., Nature, 189, 140 (1961).

- Gaby, W. L., Wolin, H. I., and Zajac, I., Cancer Res., 20, 1508 (1960).

5 James, A. T., Methods of Biochemical Analysis, edit by Glide, D., 1 (Interscience Publishers, 1961). 